Keywords: pancreatic cancer; gemcitabine; S-1; metastatic pancreatic cancer; locally advanced unresectable pancreatic cancer; individual patient data

\title{
Efficacy and safety of gemcitabine plus S-1 in pancreatic cancer: a pooled analysis of individual patient data
}

Chikuma Hamada*,1, Takuji Okusaka², Takaaki Ikari ${ }^{3}$, Hiroyuki Isayama ${ }^{4}$, Junji Furuse ${ }^{5}$, Hiroshi Ishii ${ }^{6}$, Yousuke Nakai ${ }^{4}$, Shogo Imai $^{1}$ and Shota Okamura ${ }^{1}$

${ }^{1}$ Department of Management Science, Tokyo University of Science, 6-3-1 Niijuku, Katsushika-ku, Tokyo 125-8585, Japan; ${ }^{2}$ Department of Hepatobiliary and Pancreatic Oncology, National Cancer Center Hospital, 5-1-1 Tsukiji, Chuo-ku, Tokyo 104-0045, Japan; ${ }^{3}$ Department of Internal Medicine, Tobu Chiiki Hospital, 5-14-1 Kameari, Katsushika-ku, Tokyo 125-8512, Japan; ${ }^{4}$ Department of Gastroenterology, Graduate School of Medicine, The University of Tokyo, 7-3-1 Hongo, Bunkyo-ku, Tokyo 113-8655, Japan; ${ }^{5}$ Department of Medical Oncology, Kyorin University School of Medicine, 6-20-2 Shinkawa, Mitaka, Tokyo 181-8611, Japan and 'Department of Medical Oncology, Shikoku Cancer Center, 160 Kou, Minami Umemoto, Matsuyama 791-0280, Japan

Background: Three randomised trials (GEST, JACCRO PC-01, and GEMSAP) were conducted to evaluate the efficacy of gemcitabine plus S-1 (GS) vs gemcitabine alone in patients with advanced pancreatic cancer (PC). In this pooled analysis, the efficacy and safety of GS vs gemcitabine were evaluated.

Methods: Additional follow-up was conducted and survival data were updated in each study. A total of 770 patients (gemcitabine 389; GS 381) were included in the pooled analysis. The efficacy and safety data were analysed according to disease extent: locally advanced PC (LAPC) or metastatic PC (MPC).

Results: There were 738 (95.8\%) overall survival events. In patients with LAPC $(n=193)$, the median survival was 11.83 months for gemcitabine and 16.41 months for $\mathrm{GS}$ (hazard ratio $(H R)=0.708 ; 95 \%$ confidence intervals $(\mathrm{Cl}), 0.527-0.951 ; P=0.0220$ ). In patients with MPC $(n=577)$, the median survival was 8.02 months for gemcitabine and 9.43 months for $\mathrm{GS}(\mathrm{HR}=0.872 ; 95 \% \mathrm{Cl}, 0.738-1.032$; $P=0.1102$ ). The rate of grade $3 / 4$ toxicity (rash and thrombocytopenia in LAPC; rash, diarrhoea, vomiting, and neutropaenia in MPC) was significantly higher for GS than for gemcitabine.

Conclusions: Gemcitabine plus S-1 is a viable treatment alternative to gemcitabine, which is one of the standard treatments in patients with LAPC.

Pancreatic cancer (PC) has a poor prognosis. Worldwide, $\sim 338000$ cases were newly diagnosed in 2012, and more than 330000 patients died from the disease (GLOBOCAN; Ferlay et al, 2014).

Since 1997, gemcitabine (GEM) monotherapy has been a standard treatment for advanced PC (Burris et al, 1997). For more than 10 years, various drugs and regimens have failed to prolong overall survival (OS) attributable to the use of GEM (Berlin et al, 2002; Rocha Lima et al, 2004; Louvet et al, 2005). However, several regimens have extended GEM-prolonged survival. Compared with GEM alone, GEM plus capecitabine showed a significant but small survival benefit for locally advanced PC (LAPC) and metastatic PC (MPC) patients (Cunningham et al, 2009) and GEM plus erlotinib improved survival in LAPC and MPC patients (Moore et al, 2007).

*Correspondence: Professor C Hamada; E-mail: hamada@rs.kagu.tus.ac.jp

Received 26 October 2016; revised 29 March 2017; accepted 12 April 2017; published online 4 May 2017

(C) 2017 Cancer Research UK. All rights reserved 0007 - 0920/17 
Philip et al (2009) recommended studying patients with MPC separately from those with LAPC. Despite trials showing survival benefit of GEM plus erlotinib in a population of LAPC and MPC patients, the LAP07 trial found no such benefit in LAPC patients (Hammel et al, 2016). No study has yet reported any survival benefit of GEM combination chemotherapy for LAPC.

Recent reports indicate that survival was significantly longer in patients treated with MPC, FOLFIRINOX, and GEM plus nabpaclitaxel than in patients treated with GEM (Conroy et al, 2011; Von Hoff DD et al, 2013). As treatment for LAPC, these new regimens were evaluated in some studies (Stein et al, 2016), not evaluated in randomised controlled trials. In addition, the ESMO clinical practice guidelines recommend the use of GEM monotherapy for LAPC (Ducreux et al, 2015). Moreover, it is necessary to select patients with a good performance status because these regimens are more toxic than GEM alone. Therefore, individual treatment regimens in PC should be carefully chosen.

S-1, an oral fluoropyrimidine anticancer agent that was developed in Japan, has been shown to be effective for gastric and other types of cancer (Sakuramoto et al, 2007; Koizumi et al, 2008; Yamada et al, 2013; Okamoto et al, 2010). In patients with PC, S-1 was the first drug demonstrated to be non-inferior to GEM (Ueno et al, 2013). In addition, postoperative adjuvant chemotherapy with S-1 was shown to significantly prolong OS compared with GEM (Uesaka et al, 2016).

The results of three randomised controlled clinical trials comparing the efficacy of S-1 plus GEM (GS) with that of GEM in patients with PC were reported at the American Society of Clinical Oncology meeting in 2011. Two trials were randomised phase II studies: the JACCRO PC-01 (NCT00514163; Ozaka et al, 2012) was conducted by the Japan Clinical Cancer Research Organization (JACCRO), with response rate (RR) as the primary end point, and the GEMSAP (UMIN000000498; Nakai et al, 2012), performed by the GEMSAP study group, with progression-free survival (PFS) as the primary end point. Regarding the primary end point of both trials, GS resulted in significantly better outcomes compared with GEM. The third trial was the GEST, a phase III study sponsored by Taiho Pharmaceutical Co. Ltd. (NCT00498225; Ueno et al, 2013). Although the results of this trial did not demonstrate the superiority of GS over GEM alone in improving OS (the primary end point), subgroup analyses showed that GS had favourable hazard ratios (HR) compared with GEM in subsets of patients with LAPC. A pooled analysis of previously published data focusing on LAPC has also been reported. (Yanagimoto et al, 2014).

As mentioned above, it has recently been considered clinically important to evaluate MPC and LAPC separately. In this pooled analysis, we followed up patients enroled in the three randomised controlled studies to update their outcomes and analysed individual patient data (IPD) in two patient subsets: one with MPC and one with LAPC.

\section{MATERIALS AND METHODS}

Study identification. As stated above, we comprehensively analysed the results of three trials designed to evaluate GS compared with GEM in patients with MPC and LAPC, respectively (Table 1).

Data collection and updating. Survival was additionally followed up in each trial. Taiho Pharmaceutical Co. Ltd., which was responsible for managing the GEST data, obtained IPD from the JACCRO PC-01 and GEMSAP and entered them into a database. The consolidated data were provided to the Tokyo University of Science and analysed independently. Data on the following variables were collected and evaluated: patient characteristics (sex, age, disease extent (locally advanced $v s$ distant metastasis), Eastern Cooperative Oncology Group performance status (PS), and presence or absence of biliary drainage, liver metastasis, peritoneal metastasis, and lung metastasis); laboratory data before starting treatment (white blood cell count, haemoglobin level, platelet count, blood levels of aspartate aminotransferase, alanine aminotransferase, total bilirubin, creatinine, and C-reactive protein); tumour marker levels (CEA and cancer antigen 19-9); efficacy data (OS, PFS, and RR); safety data; presence or absence of subsequent treatment; and type of subsequent treatment.

Decision criteria. To perform a pooled analysis, a coordinating committee consisting of representatives of the three research groups and the Tokyo University of Science generated statistical hypotheses and decision criteria in advance. To avoid the effect of inflated alpha errors (caused by the multiplicity of tests) on subgroup analyses of multiple end points, the improvement in OS associated with GS as compared with GEM monotherapy in patients with LAPC was designated as the primary end point. The secondary end points were, respectively, improvement in OS in patients with MPC and improvement in OS in the entire study group. In addition, efficacy (PFS and RR), safety, and other subgroup analyses were performed to comprehensively evaluate the efficacy and safety of GS.

If the primary end point was met and then efficacy (HR and absolute gains (OS/PFS), RR), safety, and heterogeneity results were totally clinically acceptable, the committee would judge GS to be a treatment option for LAPC. If the secondary end points were met and then efficacy (HR and absolute gains (OS/PFS), RR), safety, and heterogeneity results were totally clinically acceptable, the committee would judge GS to be a possible valuable treatment and a valiant treatment for further evaluation in clinical trials for evaluated population.

Statistical analysis. In the pooled analysis, the efficacy and safety analysis populations were the same as those in each study. Overall survival was defined as the time from study enrolment to death from any cause. Progression-free survival was defined as the time between study enrolment and progression of disease or death from any cause if the patient died without confirmation of disease progression, whichever came first. Post-progression survival (PPS) as post hoc analysis was defined as the time from PFS event to death from any cause. Patients who have died without confirmed progression have been dealt with censored in day 0. Response was assessed according to the Response Evaluation Criteria in Solid Tumours (RECIST), version 1.0. AEs were assessed according to the Common Terminology Criteria for Adverse Events, version 3.0.

The efficacy of GS relative to that of GEM alone was analysed using a Cox proportional hazards model stratified by study with a treatment group as the only covariate to estimate HRs with 95\% CIs and $P$-values. Heterogeneity among the three studies was also evaluated using the Wald test. Survival rate was estimated by the Kaplan-Meier method. Progression-free survival was analysed in a similar manner to OS. Response rate was calculated on the basis of the rates of CR and PR in patients with measurable lesions. The Fisher's exact test was used to compare the treatment groups, and the Wilcoxon rank-sum test was used for ordinal data. All statistical analyses were performed using SAS version 9.3 (SAS Institute Inc., Cary, NC, USA).

Each contributing study received approval from the appropriate institutional review board/ethics committee. All participants provided written informed consent. The need for ethical approval and individual informed consent for this pooled analysis were judged by each contributing study group according to the Ethical Guidelines for Epidemiological Research by the Japanese Government. 


\section{RESULTS}

The pooled analysis included 777 patients from the three studies (Table 1). Further details are available in the respective reports (Nakai et al, 2012; Ozaka et al, 2012; Ueno et al, 2013). In the GS group, seven patients (three ineligible and four not treated) were excluded from the efficacy analysis. The remaining 770 patients (full analysis set) were included in the efficacy analysis. Safety was evaluated after excluding 15 patients (five from the GEM group and 10 from the GS group) who did not receive the assigned treatment (Figure 1). OS was confirmed in 738 (95.8\%) patients.
The demographic and patient characteristics were similar between the treatment groups (Table 2).

Efficacy. In patients with LAPC, the HR for OS in the GS group relative to the GEM group, the median survival in the GEM group, and median survival in the GS group were 0.708 (95\% CI, $0.527-0.951, P=0.0220$; Figure 2), 11.83 months (95\% CI, 9.99-14.59), and 16.41 months (95\% CI, 13.54-20.01), respectively (Figure 3A). In patients with MPC, they were $0.872(95 \% \mathrm{CI}$, $0.738-1.032 ; P=0.1102), 8.02$ months (95\% CI, 7.26-8.77), and 9.43 months (95\% CI, 8.15-10.25; Figure 3B). The interaction $P$-value in (LAPC/MPC) was 0.2846. In the entire study group,

\section{Table 1. Characteristics of the trials}

\begin{tabular}{|c|c|c|c|}
\hline Study & GEST & JACCRO PC-01 & GEMSAP \\
\hline Country & Japan, Taiwan & Japan & Japan \\
\hline Study design & Phase III & r-Phase II & r-Phase II \\
\hline Primary end point & Overall survival & Response rate & Progression-free survival \\
\hline Treatment schedule for GEM & $\begin{array}{c}\text { GEM } 1000 \mathrm{mg} \mathrm{m}^{-2} \text {, days } 1,8.15 .1 \\
\text { course ( } 4 \text { weeks) }\end{array}$ & $\begin{array}{c}\text { GEM } 1000 \mathrm{mg} \mathrm{m}^{-2} \text {, days } 1,8.15 .1 \\
\text { course (4 weeks) }\end{array}$ & $\begin{array}{c}\text { GEM } 1000 \mathrm{mg} \mathrm{m}^{-2} \text {, days } 1,8.15 .1 \\
\text { course }(4 \text { weeks })\end{array}$ \\
\hline Treatment schedule for GS & $\begin{array}{l}\text { GEM } 1000 \mathrm{mg} \mathrm{m}^{-2} \text {, days } 1,8 \\
\text { S-1 } 65 \mathrm{mg} \mathrm{m}^{-2} \text {, days } 1-14 . \\
\text { One course (3 weeks) }\end{array}$ & $\begin{array}{l}\text { GEM } 1000 \mathrm{mg} \mathrm{m}^{-2} \text {, days } 1,8 \\
\text { S-1 } 80 \mathrm{mg} \mathrm{m}^{-2} \text {, days } 1-14 . \\
\text { One course (3 weeks) }\end{array}$ & $\begin{array}{l}\text { GEM } 1000 \mathrm{mg} \mathrm{m}^{-2} \text {, days } 1,15 \\
\text { S-1 } 80 \mathrm{mg} \mathrm{m}^{-2} \text {, days } 1-14 . \\
\text { One course (4 weeks) }\end{array}$ \\
\hline Major eligibility criteria & $\begin{array}{c}\text { No prior chemotherapy, locally advanced } \\
\text { or metastatic pancreatic cancer, age } \geqslant 20 \\
\text { (amended age } 20-80 \text { ), PS 0-1 }\end{array}$ & $\begin{array}{l}\text { No prior chemotherapy, locally advanced } \\
\text { or metastatic pancreatic cancer, } \\
\text { measurable lesions, age } 20-80, \text { PS 0-2 }\end{array}$ & $\begin{array}{l}\text { No prior chemotherapy, locally } \\
\text { advanced or metastatic pancreatic } \\
\text { cancer, age } 20-80 \text {, PS 0-2 }\end{array}$ \\
\hline Accrual period & July 2007 to October 2009 & March 2007 to August 2010 & July 2006 to February 2009 \\
\hline Number of sites & 75 & 16 & 6 \\
\hline $\begin{array}{l}\text { Number of registered patients } \\
\text { (GEM/GS) }\end{array}$ & $554(277 / 277)$ & $117(59 / 58)$ & $106(53 / 53)$ \\
\hline \multicolumn{4}{|l|}{ Main efficacy data (GEM/GS) } \\
\hline Response rate (\%) & $13.3 / 29.3$ & $6.8 / 28.3$ & $9.4 / 18.9$ \\
\hline $\begin{array}{l}\text { Median progression-free } \\
\text { survival (months) }\end{array}$ & $4.1 / 5.7$ & $3.78 / 6.15$ & $3.6 / 5.4$ \\
\hline Median survival time (months) & $8.8 / 10.1$ & $8.0 / 13.7$ & $8.8 / 13.5$ \\
\hline $\begin{array}{l}\text { Number of overall survival } \\
\text { events }\end{array}$ & 472 & 87 & 100 \\
\hline
\end{tabular}

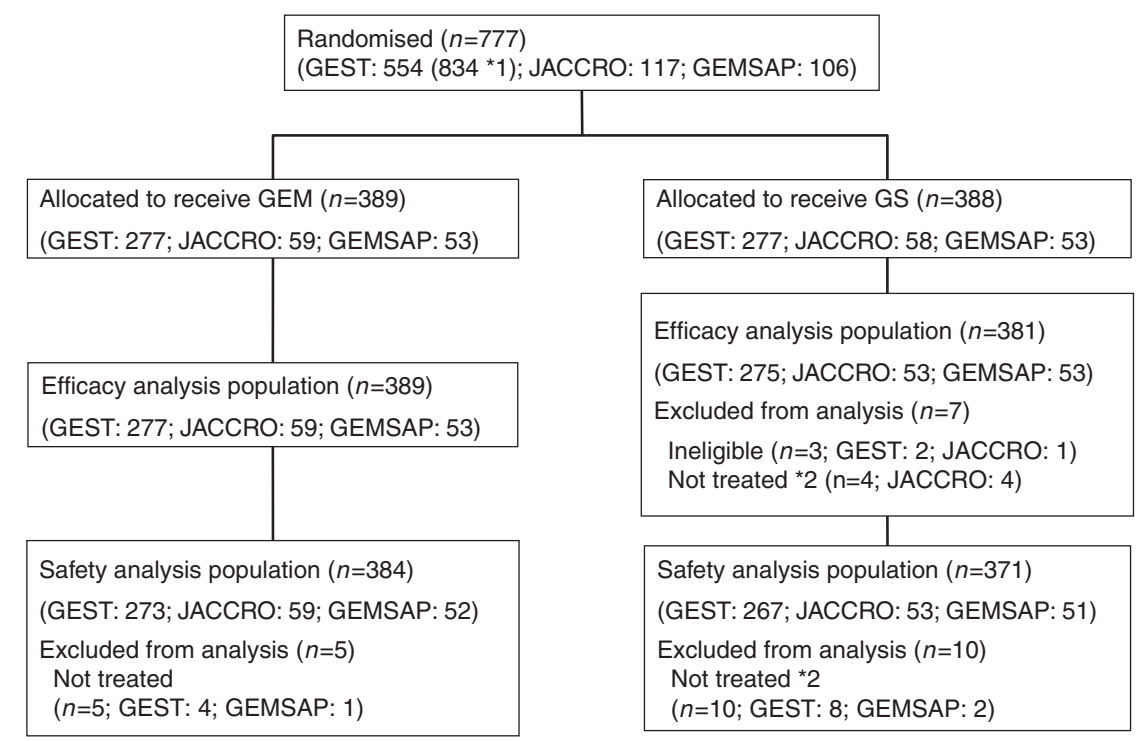

*1 The GEST trial was a three-arm study (GEM, S-1, GS); 280 patients were assigned to receive S-1 *2 The efficacy and safety analysis populations were the same as those in each study.

Figure 1. CONSORT diagram. 
they were $0.823(95 \% \mathrm{CI}, 0.712-0.952 ; P=0.0085)$, 8.74 months (95\% CI, 7.89-9.23), and 10.48 months (95\% CI, 9.59-11.70; Supplementary Table S1).

Progression-free survival was confirmed in 741 (96.2\%) patients. In patients with LAPC, the HR for PFS in the GS group relative to the GEM group, the median PFS in the GEM group, and the

Table 2. Demographic and baseline characteristics of patients

\begin{tabular}{|c|c|c|c|}
\hline Characteristic & $\begin{array}{c}\text { GEM }(n=389) \\
n(\%)\end{array}$ & $\begin{array}{c}\text { GS }(n=381) \\
n(\%)\end{array}$ & $P$ \\
\hline \multicolumn{4}{|l|}{ Sex } \\
\hline Male & $238(61.2)$ & $232(60.9)$ & \multirow[t]{2}{*}{$0.9412^{\mathrm{a}}$} \\
\hline Female & $151(38.8)$ & 149 (39.1) & \\
\hline \multicolumn{4}{|l|}{ Age (years) } \\
\hline$<65$ & $187(48.1)$ & $194(50.9)$ & \multirow[t]{2}{*}{$0.4710^{\mathrm{a}}$} \\
\hline$\geqslant 65$ & $202(51.9)$ & $187(49.1)$ & \\
\hline \multicolumn{4}{|l|}{ PS } \\
\hline 0 & $258(66.3)$ & $247(64.8)$ & \multirow{3}{*}{$0.7024^{b}$} \\
\hline 1 & 128 (32.9) & $133(34.9)$ & \\
\hline 2 & $3(0.8)$ & $1(0.3)$ & \\
\hline \multicolumn{4}{|l|}{ Disease stage } \\
\hline Locally advanced & 97 (24.9) & $96(25.2)$ & \multirow{2}{*}{$0.9340^{\mathrm{a}}$} \\
\hline Metastatic & $292(75.1)$ & $285(74.8)$ & \\
\hline \multicolumn{4}{|l|}{ Biliary drainage } \\
\hline No & 275 (70.7) & $284(74.5)$ & \multirow[t]{3}{*}{$0.2060^{\mathrm{a}}$} \\
\hline & $103(26.5)$ & $85(22.3)$ & \\
\hline No data & $11(2.8)$ & $12(3.2)$ & \\
\hline \multicolumn{4}{|l|}{ Target lesion } \\
\hline No & $36(9.3)$ & $33(8.7)$ & \multirow[t]{2}{*}{$0.8018^{\mathrm{a}}$} \\
\hline Yes & $353(90.7)$ & 348 (91.3) & \\
\hline \multicolumn{4}{|l|}{ Liver metastasis } \\
\hline No & $224(57.6)$ & $215(56.4)$ & \multirow[t]{2}{*}{$0.7711^{\mathrm{a}}$} \\
\hline Yes & $165(42.4)$ & $166(43.6)$ & \\
\hline \multicolumn{4}{|c|}{ Peritoneal metastasis } \\
\hline No & $339(87.1)$ & $341(89.5)$ & \multirow[t]{2}{*}{$0.3154^{\mathrm{a}}$} \\
\hline Yes & $50(12.9)$ & $40(10.5)$ & \\
\hline \multicolumn{4}{|l|}{ Lung metastasis } \\
\hline No & $379(97.4)$ & 364 (95.5) & \multirow[t]{2}{*}{$0.1734^{\mathrm{a}}$} \\
\hline Yes & $10(2.6)$ & $17(4.5)$ & \\
\hline \multicolumn{4}{|c|}{ 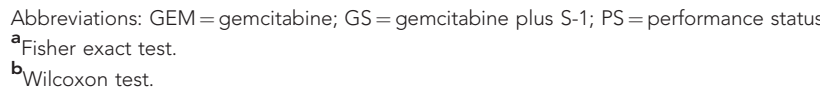 } \\
\hline
\end{tabular}

median PFS in the GS group were, respectively, 0.597 (95\% CI, 0.441-0.808; $P=0.0008$; Supplementary Figure S1), 5.78 months (95\% CI, 4.44-6.97), and 11.76 months (95\% CI, 8.05-12.71). In patients with MPC, they were 0.668 (95\% CI, 0.564-0.790; $P<0.0001$ ), 3.01 months (95\% CI, 2.46-3.94), and 5.36 months (95\% CI, 4.44-5.68). In the entire study group, they were 0.655 (95\% CI, $0.566-0.758, P<0.0001$ ), 3.81 months (95\% CI, 3.02-4.37), and 5.78 months (95\% CI, 5.36-6.74; Supplementary Table S1).

The median PPS in the GEM group and GS group were, respectively, 4.90 (95\% CI, 3.75-5.85) months and 3.81 (95\% CI, 2.73-6.05) months in LAPC patients, and 4.01 (95\% CI, 3.12-4.63) months and 3.12 (95\% CI, 2.76-3.68) months in MPC patients.

The RR was significantly higher in the GS group than in the GEM group for each subgroup (Supplementary Table S2).

Safety. In this study, AEs were separately tabulated for patients with LAPC and those with MPC (Table 3). Overall, the incidences of AEs tended to be higher in the GS group than in the GEM group. The incidences of the following grade 3 or higher AEs were significantly higher in the GS group: rash and thrombocytopaenia in patients with LAPC and rash, diarrhoea, vomiting, and neutropaenia in patients with MPC $(P<0.05)$.

Second-line treatment. Among patients with LAPC, $62.9 \%$ $(n=61)$ of the GEM group and $65.6 \%(n=63)$ of the GS group and, among patients with MPC, $68.8 \%(n=201)$ of the GEM group and $61.1 \%(n=174)$ of the GS group received second-line treatment.

In the GEM group, the main second-line treatments in patients with LAPC and those with MPC were, respectively, GEM-based regimens in $20.6 \%(n=20)$ and $11.6 \%(n=34)$, S1-based regimens in $34.0 \%(n=33)$ and $43.8 \%(n=128)$, GS in $6.2 \%(n=6)$ and $10.6 \%(n=31)$, chemoradiation or radiation in $0.0 \%(n=0)$ and $1.0 \%(n=3)$, and surgical therapy in $1.0 \%(n=1)$ and $1.0 \%$ $(n=3)$. The crossover rate, reflecting regimens including S-1 as the second-line chemotherapy, was $40.2 \%(n=39)$ in patients with LAPC and $54.5 \%(n=159)$ in patients with MPC.

In the GS group, the main second-line treatments in patients with LAPC and those with MPC were, respectively, GEM-based regimens in $33.3 \%(n=32)$ and $22.5 \%(n=64)$, S1-based regimens in $12.5 \%(n=12)$ and $7.4 \%(n=21)$, GS in $9.4 \%(n=9)$ and $18.2 \%$ $(n=52)$, chemoradiation or radiation in $8.3 \%(n=8)$ and $1.8 \%$ $(n=5)$, and surgical therapy in $1.0 \%(n=1)$ and $0.4 \%(n=1)$.

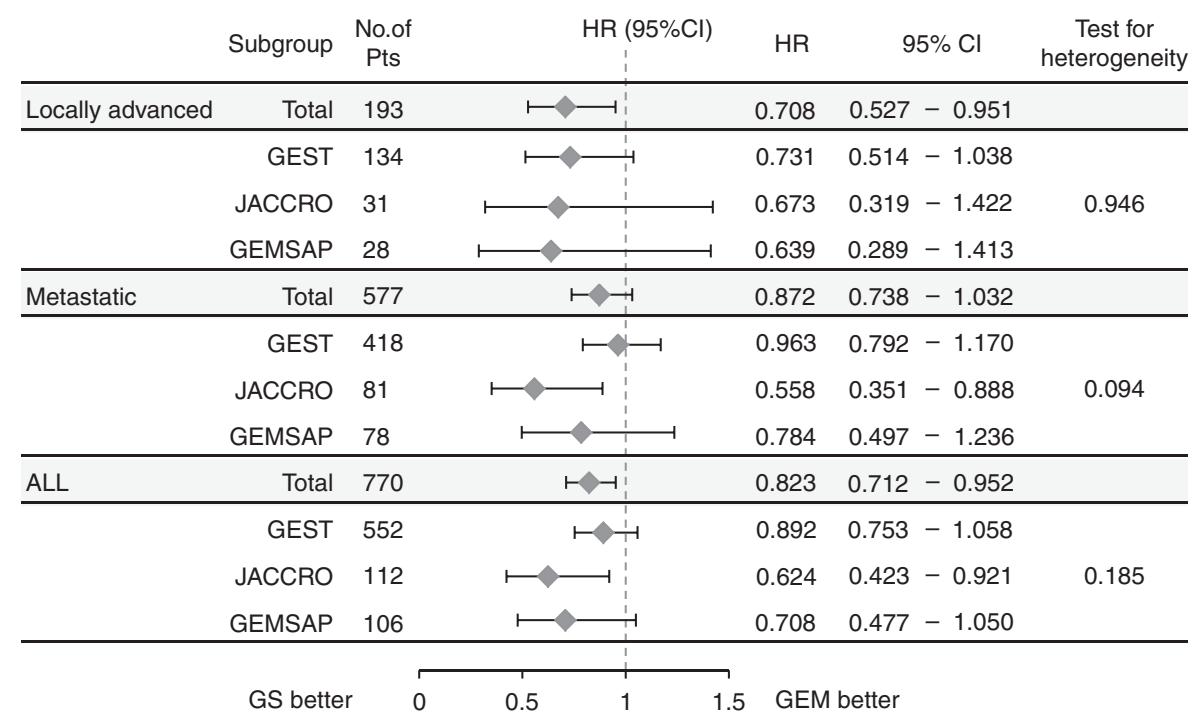

Figure 2. Cox's proportional hazards model and test for heterogeneity (OS). 
A

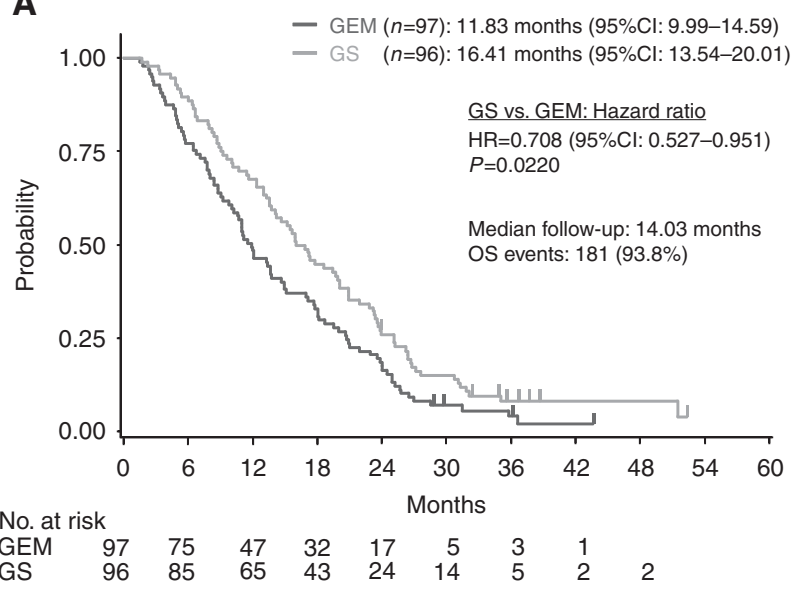

B $\quad-$ GEM (n=292): 8.02 months (95\%Cl: 7.26-8.77)

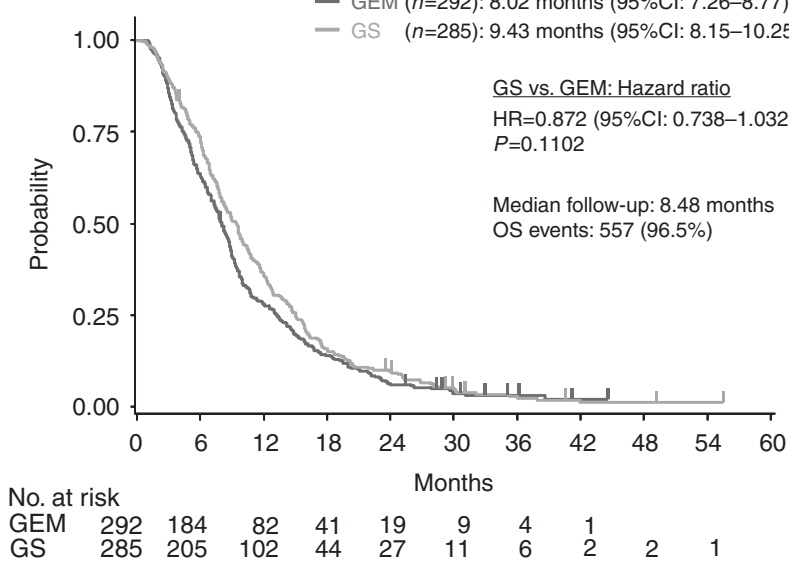

Figure 3. The Kaplan-Meier plot for overall survival in patients with locally advanced pancreatic cancer (A) and patients with metastatic pancreatic cancer (B).

\section{DISCUSSION}

In our pooled analysis, we showed that GS has survival benefit compared with GEM in LAPC patients $(\mathrm{HR}=0.708 ; P=0.0220)$ but not in MPC $(\mathrm{HR}=0.872 ; P=0.1102)$. The additional followup resulted in more mature OS data for $95.8 \%$ of the analysis set. Both treatment groups had similar background characteristics. As the comparability was maintained, a pooled analysis was considered appropriate.

Another oral fluoropyrimidine, capecitabine, was evaluated in LAPC and MPC patients. The combination of GEM plus capecitabine had significantly more survival benefit than GEM alone, with HR of 0.86 in meta-analysis of two Phase III studies. However, this benefit was not reported for LAPC and MPC separately. In this pooled analysis, GS conferred survival benefit over GEM, with HR of 0.823 in the entire study population. Gemcitabine plus S-1 might have the comparable efficacy to GEM plus capecitabine in the entire population.

It remains unclear why LAPC patients ( $v s$ MPC patients) had a better HR for OS. The difference in the median PFS between the GS and GEM groups was $\sim 6$ months longer in LAPC patients and $\sim 2$ months longer in MPC patients, while the median PPS was only 1 month shorter in the GS group than in the GEM group in both LAPC and MPC patients. The proportion of patients who underwent any subsequent treatments was similar between MPC and LAPC patients. The proportion of patients receiving subsequent surgery and radiotherapy was very low in both treatment groups in LAPC patients. Therefore, this survival benefit in GS for LAPC patients might largely be attributed to the better PFS of those receiving GS treatment.

In LAPC, there was a significant PFS benefit of GS vs GEM and a significantly higher RR in patients treated with GS than those treated with GEM. Furthermore, it was reported that postoperative adjuvant chemotherapy with S-1 (compared with GEM) significantly increased OS and relapse-free survival in patients with resected PC (Uesaka et al, 2016). Therefore, the addition of S-1 to GEM may extend control to new metastatic lesions, especially in those with LAPC. The higher RR and control of new metastatic lesions might explain why GS increased PFS in LAPC patients.

In MPC, GS failed to confer a survival benefit over GEM for two possible reasons. One reason might be the intensity of chemotherapy for MPC. The HRs for the secondary end point of OS were rather inconsistent and slightly heterogeneous among the three studies $(P=0.094$; Figure 2$)$. The three studies in our analysis enroled the majority of patients at about the same time in Japan, used similar eligibility criteria, and contained a GEM control arm receiving the same regimen. However, the GS regimens differed slightly between the three studies (Table 1). The initial dose of S-1 was the standard dose $\left(80 \mathrm{mg} \mathrm{m}^{-2}\right.$ per day) in the JACCRO PC-01 and GEMSAP and $15 \mathrm{mg} \mathrm{m}^{-2}$ lower than the standard dose (65 $\mathrm{mg} \mathrm{m}^{-2}$ per day) in the GEST. All three studies used the same standard dose of GEM (1000 $\mathrm{mg} \mathrm{m}^{-2}$ ) but on different administration schedules. Among the three GS regimens, the JACCRO PC01 regimen was the most potent, and seemed to be the most effective means for improving OS (Figure 2). FOLFIRINOX, a potent four-drug intense combination regimen, and GEM plus nab-paclitaxel, comprising a full-dose GEM plus nab-paclitaxel, were more effective than GEM alone in MPC patients (Conroy et al, 2011; Von Hoff et al, 2013). These findings suggest that firstline treatment with more potent regimens may be required in MPC therapy. Dose reduction of S-1 from the standard dose and the modification of the GEM administration schedule may influence the efficacy of GS in MPC. A second reason might be the impact of subsequent treatment. In our study, the proportion of MPC patients who underwent subsequent treatment differed between those treated with GEM (68.8\%) and those treated with GS (61.1\%). The total proportion of patients who received GEM-based and S1-based chemotherapy differed between the GEM arm (66.0\%) and GS arm (48.1\%). When the three studies in this pooled analysis were conducted, FOLFIRINOX and nab-paclitaxel were not available and GEM and S-1 (5-FU) were the active second-line chemotherapies for PC in Japan and Taiwan. Therefore, subsequent treatment most likely contributed to the survival benefit in MPC patients treated with GEM.

On the basis of certain AEs (rash, diarrhoea, and vomiting), GS (compared to GEM) had a less favourable safety profile. Although no patient-reported outcomes were collected, these non-haematological toxicities might decrease the QOL in the GS arm. In this analysis, AEs were separately evaluated in patients with LAPC and those with MPC. Although the duration of treatment was longer in patients with LAPC, AEs in patients with LAPC were not markedly increased. These findings may indicate that toxicity accumulation in each treatment group is low.

Our pooled analysis has some limitations. First, it included two randomised phase II studies and only one phase III study. However, only IPD from these three studies comparing GEM and GS was available when the pooled analysis study committee was formed. Second, the number of LAPC patients in this analysis was small. However, there was no heterogeneity in pooled HRs for OS (the primary end point) across the three trials $(P=0.946)$ in LAPC patients (Figure 2$)$. Therefore, the primary end point of OS was consistent among the three studies. Third, although the subgroup (LAPC/MPC) showed a little interaction between GS and GEM, the observed efficacy (HR and 
Table 3. Adverse events (locally advanced/metastatic)

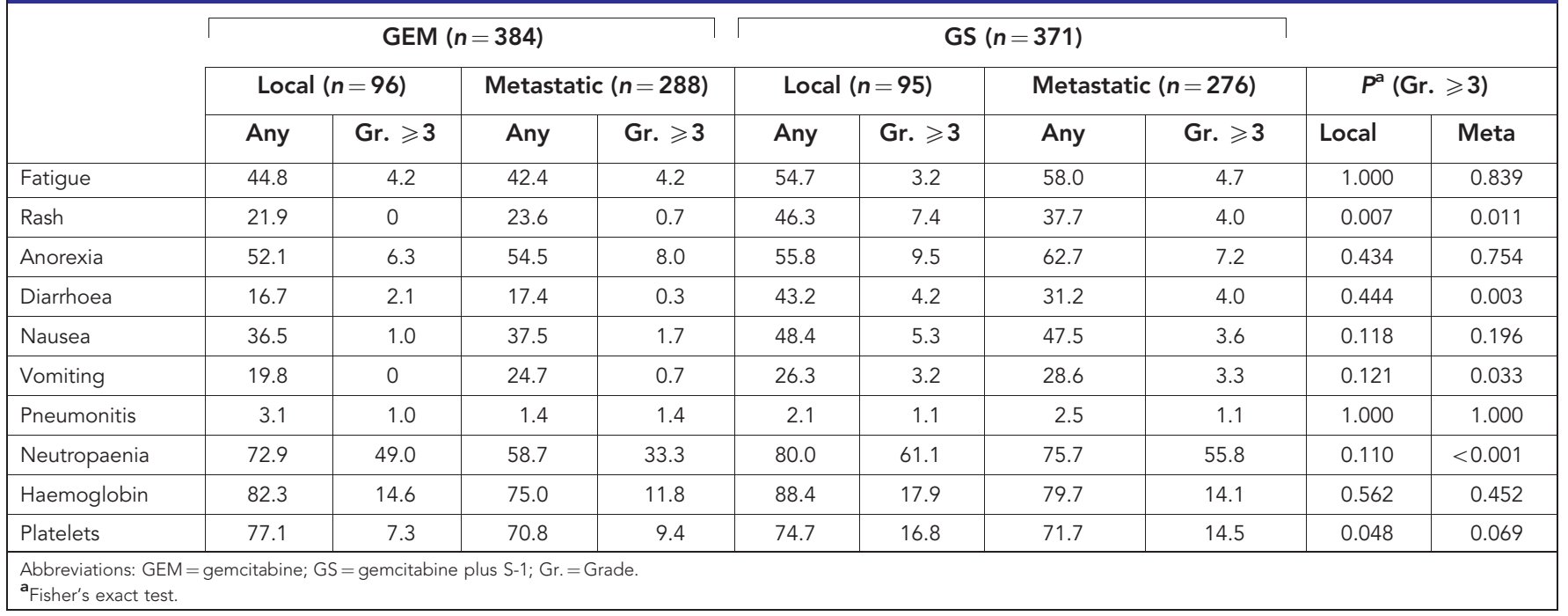

absolute gains) of GS compared with GEM in LAPC was clinically important (Cherny et al, 2015). Fourth, all patients enroled in these studies were ethnically East Asian, from Japan and Taiwan. It was reported that the pharmacokinetics and pharmacodynamics of S-1 might be different between European and East Asian patients, and that grade 3 or 4 gastrointestinal toxicities were more common in European patients than in East Asian patients (Chuah et al, 2011). Therefore, the GS dose and schedule might need to be more carefully adjusted in European patients.

Finally, compared with GEM, GS in the entire study population was associated with better OS and PFS. However, given the difference in GS efficacy between LAPC and MPC patients and given the degree of absolute gains of efficacy, we concluded that OS and PFS should be separately assessed for LAPC and MPC and might not be a possible valuable treatment in the entire study population.

In conclusion, GS should be considered a viable treatment alternative to GEM, which is one of the standard treatments in patients with LAPC. The results of our analysis reconfirmed that outcome depends on whether patients have LAPC or MPC.

\section{ACKNOWLEDGEMENTS}

Research funds and the data of the GEST trial were provided to the Tokyo University of Science by Taiho Pharmaceutical Co., Ltd., under a research contract.

\section{CONFLICT OF INTEREST}

$\mathrm{CH}$ has received consultancies from Taiho Pharmaceutical Co., Ltd. TO has received honoraria from Taiho Pharmaceutical Co., Ltd., Eli Lilly Japan KK, consultancies and research funding from Eli Lilly Japan KK and Taiho Pharmaceutical Co., Ltd. H Isayama has received honoraria from Taiho Pharmaceutical Co., Ltd. and Eli Lilly Japan KK, and research funding from Taiho Pharmaceutical Co., Ltd. JF has received honoraria from Taiho Pharmaceutical Co., Ltd. and Eli Lilly Japan KK, consultancies from Taiho Pharmaceutical Co., Ltd., and research funding from Taiho Pharmaceutical Co., Ltd. and Eli Lilly Japan KK H Ishii, has received honoraria from Taiho Pharmaceutical Co., Ltd. and Eli
Lilly Japan KK, and research funding from Taiho Pharmaceutical Co., Ltd. The remaining authors declare no conflict of interest.

\section{DISCLAIMER}

The funders had no involvement in the design of the study; the analysis and interpretation of the data; the writing of the article; or the decision to submit the article for publication.

\section{REFERENCES}

Berlin JD, Catalano P, Thomas JP, Kugler JW, Haller DG, Benson 3rd AB (2002) Phase III study of gemcitabine in combination with fluorouracil versus gemcitabine alone in patients with advanced pancreatic carcinoma: Eastern Cooperative Oncology Group Trial E2297. J Clin Oncol 20: 3270-3275.

Burris 3rd HA, Moore MJ, Andersen J, Green MR, Rothenberg ML, Modiano MR, Cripps MC, Portenoy RK, Storniolo AM, Tarassoff P, Nelson R, Dorr FA, Stephens CD, Von Hoff DD (1997) Improvements in survival and clinical benefit with gemcitabine as first-line therapy for patients with advanced pancreas cancer: a randomized trial. J Clin Oncol 15: 2403-2413.

Cherny NI, Sullivan R, Dafni U, Kerst JM, Sobrero A, Zielinski C, de Vries EG, Piccart MJ (2015) A standardised, generic, validated approach to stratify the magnitude of clinical benefit that can be anticipated from anti-cancer therapies: the European Society for Medical Oncology Magnitude of Clinical Benefit Scale (ESMO-MCBS). Ann Oncol 26(8): 1547-1573.

Chuah B, Goh BC, Lee SC, Soong R, Lau F, Mulay M, Dinolfo M, Lim SE, Soo R, Furuie T, Saito K, Zergebel C, Rosen LS (2011) Comparison of the pharmacokinetics and pharmacodynamics of S-1 between European and East Asian patients. Cancer Sci 102(2): 478-483.

Conroy T, Desseigne F, Ychou M, Bouché O, Guimbaud R, Bécouarn Y, Adenis A, Raoul JL, Gourgou-Bourgade S, de la Fouchardière C, Bennouna J, Bachet JB, Khemissa-Akouz F, Péré-Vergé D, Delbaldo C, Assenat E, Chauffert B, Michel P, Montoto-Grillot C, Ducreux M, Groupe Tumeurs Digestives of Unicancer; PRODIGE Intergroup (2011) FOLFIRINOX versus gemcitabine for metastatic pancreatic cancer. $N$ Engl J Med 364: 1817-1825.

Cunningham D, Chau I, Stocken DD, Valle JW, Smith D, Steward W, Harper PG, Dunn J, Tudur-Smith C, West J, Falk S, Crellin A, Adab F, Thompson J, Leonard P, Ostrowski J, Eatock M, Scheithauer W, Herrmann R, Neoptolemos JP (2009) Phase III randomized comparison of gemcitabine versus gemcitabine plus capecitabine in patients with advanced pancreatic cancer. J Clin Oncol 27: 5513-5518. 
Ducreux M, Cuhna AS, Caramella C, Hollebecque A, Burtin P, Goéré D, Seufferlein T, Haustermans K, Van Laethem JL, Conroy T, Arnold D, ESMO Guidelines Committee (2015) Cancer of the pancreas: ESMO Clinical Practice guidelines for diagnosis, treatment and follow-up. Ann Oncol 26(suppl 5): v56-v68.

Ferlay JSI, Ervik M, Dikshit R, Eser S, Mathers C, Rebelo M, Parkin DM, Forman D, Bray F, GLOBOCAN (2012) v1.0, Cancer Incidence and Mortality Worldwide: IARC CancerBase No. 11. Available from http:// globocan.iarc.fr (accessed on 15 January 2014).

Hammel P, Huguet F, van Laethem JL, Goldstein D, Glimelius B, Artru P, Borbath I, Bouché O, Shannon J, André T, Mineur L, Chibaudel B, Bonnetain F, Louvet C, LAP07 Trial Group (2016) Effect of chemoradiotherapy vs chemotherapy on survival in patients with locally advanced pancreatic cancer controlled after 4 months of gemcitabine with or without erlotinib: the LAP07 randomized clinical trial. JAMA 315(17): 1844-1853.

Koizumi W, Narahara H, Hara T, Takagane A, Akiya T, Takagi M, Miyashita K, Nishizaki T, Kobayashi O, Takiyama W, Toh Y, Nagaie T, Takagi S, Yamamura Y, Yanaoka K, Orita H, Takeuchi M (2008) S-1 plus cisplatin versus S-1 alone for first-line treatment of advanced gastric cancer (SPIRITS trial): a phase III trial. Lancet Oncol 9: 215-221.

Louvet C, Labianca R, Hammel P, Lledo G, Zampino MG, André T, Zaniboni A, Ducreux M, Aitini E, Taïeb J, Faroux R, Lepere C, de Gramont A, GERCOR; GISCAD (2005) Gemcitabine in combination with oxaliplatin compared with gemcitabine alone in locally advanced or metastatic pancreatic cancer: results of a GERCOR and GISCAD phase III trial. J Clin Oncol 23: 3509-3516.

Moore MJ, Goldstein D, Hamm J, Figer A, Hecht JR, Gallinger S, Au HJ, Murawa P, Walde D, Wolff RA, Campos D, Lim R, Ding K, Clark G, Voskoglou-Nomikos T, Ptasynski M, Parulekar W, National Cancer Institute of Canada Clinical Trials Group (2007) Erlotinib plus gemcitabine compared with gemcitabine alone in patients with advanced pancreatic cancer: a phase III trial of the National Cancer Institute of Canada Clinical Trials Group. J Clin Oncol 25: 1960-1966.

Nakai Y, Isayama H, Sasaki T, Sasahira N, Tsujino T, Toda N, Kogure H, Matsubara S, Ito Y, Togawa O, Arizumi T, Hirano K, Tada M, Omata M, Koike K (2012) A multicentre randomised phase II trial of gemcitabine alone vs gemcitabine and S-1 combination therapy in advanced pancreatic cancer: GEMSAP study. Br J Cancer 106: 1934-1939.

Okamoto I, Yoshioka H, Morita S, Ando M, Takeda K, Seto T, Yamamoto N, Saka H, Asami K, Hirashima T, Kudoh S, Satouchi M, Ikeda N, Iwamoto Y, Sawa T, Miyazaki M, Tamura K, Kurata T, Fukuoka M, Nakagawa K (2010) Phase III trial comparing oral S-1 plus carboplatin with paclitaxel plus carboplatin in chemotherapy-naive patients with advanced non-small-cell lung cancer: results of a west Japan oncology group study. J Clin Oncol 28: 5240-5246.

Ozaka M, Matsumura Y, Ishii H, Omuro Y, Itoi T, Mouri H, Hanada K, Kimura Y, Maetani I, Okabe Y, Tani M, Ikeda T, Hijioka S, Watanabe R, Ohoka S, Hirose Y, Suyama M, Egawa N, Sofuni A, Ikari T, Nakajima T (2012) Randomized phase II study of gemcitabine and S-1 combination versus gemcitabine alone in the treatment of unresectable advanced pancreatic cancer (Japan Clinical Cancer Research Organization PC-01 study). Cancer Chemother Pharmacol 69: 1197-1204.

Philip PA, Mooney M, Jaffe D, Eckhardt G, Moore M, Meropol N, Emens L, O’Reilly E, Korc M, Ellis L, Benedetti J, Rothenberg M, Willett C, Tempero M, Lowy A, Abbruzzese J, Simeone D, Hingorani S, Berlin J, Tepper J (2009) Consensus report of the national cancer institute clinical trials planning meeting on pancreas cancer treatment. J Clin Oncol 27: 5660-5669.

Rocha Lima CM, Green MR, Rotche R, Miller Jr WH, Jeffrey GM, Cisar LA, Morganti A, Orlando N, Gruia G, Miller LL (2004) Irinotecan plus gemcitabine results in no survival advantage compared with gemcitabine monotherapy in patients with locally advanced or metastatic pancreatic cancer despite increased tumor response rate. J Clin Oncol 22: 3776-3783.

Sakuramoto S, Sasako M, Yamaguchi T, Kinoshita T, Fujii M, Nashimoto A, Furukawa H, Nakajima T, Ohashi Y, Imamura H, Higashino M, Yamamura Y, Kurita A, Arai K (2007) Adjuvant chemotherapy for gastric cancer with S-1, an oral fluoropyrimidine. N Engl J Med 357: 1810-1820.

Stein SM, James ES, Deng Y, Cong X, Kortmansky JS, Li J, Staugaard C, Indukala D, Boustani AM, Patel V, Cha $\mathrm{CH}$, Salem RR, Chang B, Hochster HS, Lacy J (2016) Final analysis of a phase II study of modified FOLFIRINOX in locally advanced and metastatic pancreatic cancer. Br J Cancer 114: 737-743.

Ueno H, Ioka T, Ikeda M, Ohkawa S, Yanagimoto H, Boku N, Fukutomi A, Sugimori K, Baba H, Yamao K, Shimamura T, Sho M, Kitano M, Cheng AL, Mizumoto K, Chen JS, Furuse J, Funakoshi A, Hatori T, Yamaguchi T, Egawa S, Sato A, Ohashi Y, Okusaka T, Tanaka M (2013) Randomized phase III study of gemcitabine plus S-1, S-1 alone, or gemcitabine alone in patients with locally advanced and metastatic pancreatic cancer in Japan and Taiwan: GEST study. J Clin Oncol 31: 1640-1648.

Uesaka K, Boku N, Fukutomi A, Okamura Y, Konishi M, Matsumoto I, Kaneoka Y, Shimizu Y, Nakamori S, Sakamoto H, Morinaga S, Kainuma O, Imai K, Sata N, Hishinuma S, Ojima H, Yamaguchi R, Hirano S, Sudo T, Ohashi Y, JASPAC 01 Study Group (2016) Adjuvant chemotherapy of S-1 versus gemcitabine for resected pancreatic cancer: a phase 3, open-label, randomised, non-inferiority trial (JASPAC 01). Lancet 388: 248-257.

Von Hoff DD, Ervin T, Arena FP, Chiorean EG, Infante J, Moore M, Seay T, Tjulandin SA, Ma WW, Saleh MN, Harris M, Reni M, Dowden S, Laheru D, Bahary N, Ramanathan RK, Tabernero J, Hidalgo M, Goldstein D, Van Cutsem E, Wei X, Iglesias J, Renschler MF (2013) Increased survival in pancreatic cancer with nab-paclitaxel plus gemcitabine. N Engl J Med 369: 1691-1703.

Yamada Y, Takahari D, Matsumoto H, Baba H, Nakamura M, Yoshida K, Yoshida M, Iwamoto S, Shimada K, Komatsu Y, Sasaki Y, Satoh T, Takahashi K, Mishima H, Muro K, Watanabe M, Sakata Y, Morita S, Shimada Y, Sugihara K (2013) Leucovorin, fluorouracil, and oxaliplatin plus bevacizumab versus S-1 and oxaliplatin plus bevacizumab in patients with metastatic colorectal cancer (SOFT): an open-label, non-inferiority, randomised phase 3 trial. Lancet Oncol 14: 1278-1286.

Yanagimoto H, Ishii H, Nakai Y, Ozaka M, Ikari T, Koike K, Ueno H, Ioka T, Satoi S, Sho M, Okusaka T, Tanaka M, Shimokawa T, Kwon AH, Isayama H (2014) Improved survival with combined gemcitabine and S-1 for locally advanced pancreatic cancer: pooled analysis of three randomized studies. J Hepatobiliary Pancreat Sci 21: 761-766.

This work is published under the standard license to publish agreement. After 12 months the work will become freely available and the license terms will switch to a Creative Commons AttributionNonCommercial-Share Alike 4.0 Unported License.

Supplementary Information accompanies this paper on British Journal of Cancer website (http://www.nature.com/bjc) 